\title{
Developmental Regulation of Sensory Neurite Growth by the Tumor Necrosis Factor Superfamily Member LIGHT
}

\author{
Núria Gavaldà, Humberto Gutierrez, and Alun M. Davies \\ School of Biosciences, Cardiff University, Cardiff CF10 3US, United Kingdom
}

\begin{abstract}
In a PCR screen to identify novel cytokine candidates involved in neuronal development, we identified transcripts for the tumor necrosis factor superfamily member 14 (TNFSF14), generally known as LIGHT (lymphotoxin-related inducible ligand that competes for glycoprotein D binding to herpesvirus entry mediator on T cells), together with its receptors, lymphotoxin- $\beta$ receptor (LT $\beta R$ ) and TNF family receptor herpesvirus entry mediator (HVEM), in the experimentally tractable sensory neurons of the mouse nodose ganglion. Immunocytochemistry revealed coexpression of LIGHT and its receptors in all nodose ganglion neurons in neonates. Enhancing LIGHT signaling in these neurons by overexpressing LIGHT inhibited BDNF-promoted neurite growth during a narrow window of development in the immediate perinatal period without affecting neuronal survival. Overexpressing a LIGHT mutant that selectively activates HVEM, but not one that selectively activates LT $\beta$ R, also inhibited BDNF-promoted growth, suggesting that neurite growth inhibition is mediated via HVEM. Blocking HVEM signaling by a function-blocking anti-HVEM antibody significantly enhanced neurite growth from nodose neurons grown both with and without BDNF. Likewise, neurons from LIGHT-deficient neonates exhibited significantly greater neurite growth than neurons from wild-type littermates in both the presence and absence of BDNF. LIGHT overexpression significantly inhibited NF- $\kappa$ B activity, while preventing LIGHT-induced NF- $\kappa$ B inhibition by overexpressing the $\mathrm{p} 65$ and p 50 NF- $\kappa$ B subunits prevented LIGHTmediated growth inhibition. Together, these findings show that LIGHT/HVEM signaling negatively regulates neurite growth from developing sensory neurons via NF- $\kappa \mathrm{B}$ inhibition.
\end{abstract}

Key words: development; sensory neurons; TNF $\alpha$; neurite; neurotrophin; transcription factor; knock-out mice

\section{Introduction}

Numerous locally acting and diffusible signaling molecules control the growth and guidance of axons to their targets as well as terminal arborization within their targets. These molecules bind to receptors on the advancing axons to influence growth rate, direction and branching, and are derived from a wide variety of cells en route to and within their final targets. Many of the molecules that influence the growth and morphology of neural processes also regulate neuronal survival, notably, neurotrophic factors of the neurotrophin, GDNF, and gp130 cytokine families (Davies, 2003). Recently, several members of the tumor necrosis factor superfamily (TNFSF) have been implicated in regulating the growth of neural processes. Most strikingly, a GITRL/GITR autocrine loop in sympathetic neurons has been shown to be crucial for NGF-promoted axonal growth, but not survival, during a brief developmental window in the immediate postnatal period (O'Keeffe et al., 2008).

The 19 members of the TNFSF play critical roles in the development and function of the immune system, and are recognized

\footnotetext{
Received July 29, 2008; revised Dec. 3, 2008; accepted Dec. 23, 2008.

This work was supported by a grant from the Wellcome Trust. N.G. was a fellow of the Beatriu de Pinós Fellowship (Generalitat de Catalunya, Spain). We are very grateful to Carl Ware for the LIGHT and LIGHT-G119E plasmids, Shie-Liang Hsieh for the LIGHT-R228E plasmid, Patricia Spear for the anti-HVEM blocking antibody, and Klaus Pfeffer for the LIGHT knock-out mice.

Correspondence should be addressed to Alun M. Davies at the above address. E-mail: daviesalun@cf.ac.uk. D01:10.1523/JNEUROSCI.3566-08.2009

Copyright $\odot 2009$ Society for Neuroscience $\quad 0270-6474 / 09 / 291599-09 \$ 15.00 / 0$
}

increasingly as having diverse roles in other tissues and organs (Hehlgans and Pfeffer, 2005). These cytokines are, for the most part, expressed as type II transmembrane glycoproteins that are active as membrane-bound ligands and as soluble ligands after cleavage from the cell membrane by the action of specific metalloproteinases. TNFSF ligands bind to one or more members of the TNF receptor superfamily (TNFRSF) which are classified into three groups: those containing a proapoptotic death domain, those lacking a death domain, and a group of decoy receptors that do not transmit any signal (Grivennikov et al., 2006).

In a PCR screen for additional members of the TNFSF involved in regulating neuronal development, we found transcripts for LIGHT (also known as TNFSF14) and its receptors TNF family receptor herpesvirus entry mediator (HVEM) (TNFRSF14) and lymphotoxin- $\beta$ receptor (LT $\beta$ R) (TNFRSF3) in the perinatal mouse nodose ganglion, a population of enteroceptive sensory neurons that mostly depends on BDNF for survival at this stage of development both in vitro (Davies et al., 1993) and in vivo (ElShamy and Ernfors, 1997). Although a decoy receptor for LIGHT, DcR3, has been described in humans, the existence of a mouse homolog has not been described and is considered unlikely (Gommerman and Browning, 2003; Bossen et al., 2006). LIGHT has multiple functions in the immune system and has been implicated in the regulation of cell proliferation and survival in several tissues and organs (Ware, 2005; Murphy et al., 2006; Pierer et al., 2007), but has no known role in the nervous system. HVEM and LT $\beta$ R lack death domains and interact with adaptors 
of the TRAF family to modulate several signaling pathways including the NF- $\kappa \mathrm{B}$ transcription family (Grivennikov et al., 2006), which has been implicated in regulating neurite growth from neonatal nodose ganglion neurons (Gutierrez et al., 2005; Gallagher et al., 2007). Here we report a novel function for LIGHT as a negative regulator of neurite growth in nodose sensory neurons by a mechanism involving the HVEM receptor and $\mathrm{NF}-\kappa \mathrm{B}$ signaling inhibition.

\section{Materials and Methods}

Real-time PCR quantification of mRNA levels. Total RNA was extracted with the RNeasy Mini extraction kit (Qiagen) from nodose ganglion, superior cervical ganglion (SCG), trigeminal ganglion, hippocampus and cortex obtained from neonatal CD-1 mice as well as from embryonic and postnatal CD-1 mice but only from nodose ganglion. RNA was reverse transcribed for $1 \mathrm{~h}$ at $45^{\circ} \mathrm{C}$ with the AffinityScript kit (Stratagene) in a 25 $\mu \mathrm{l}$ reaction according to the manufacturer's instructions. We amplified $2.5 \mu \mathrm{l}$ aliquots of the reverse transcriptase reaction in a $25 \mu \mathrm{l}$ reaction volume using the Brilliant QPCR core reagent kit (Stratagene). The respective forward and reverse primers for real-time PCR were: LIGHT, $5^{\prime}$-TGG GCA ATC TTC AAA TCA G- ${ }^{\prime}$ and $5^{\prime}$-GCA TCA GAA GCA TAA ATA CC-3'; HVEM, 5' -GTC TAC TAC GTT GTG TCC ATC C-3' and 5'-GTC TTG TCA CCC AGA ATT TGT TC-3'; LT $\beta$ R, 5G TCG CTG GTC CTC- $3^{\prime}$ and $5^{\prime}$-GAA ATG TGG GTC GGC TCT TG-3'; GAPDH, $5^{\prime}$-AAG GAA AGT GTC AGA GTT G-3' and $5^{\prime}$-ACC CTG CTT GTA TTG GAA-3'. For LIGHT PCR a specific beacon was used (5'-CGC GAC CTC GCT CCT GGG CTC CAT CGC G-3') and for HVEM PCR a Taqman was also used ( $5^{\prime}$-AGG CTG TCT CCT CCT CGG TCT CAG$\left.3^{\prime}\right)$. PCR was performed with a Mx3000P (Stratagene) and the reactions were as follow: 45 cycles of $95^{\circ} \mathrm{C}$ for $30 \mathrm{~s}, 57^{\circ} \mathrm{C}$ for $1 \mathrm{~min}$ (for LT $\beta R$ ) or $51^{\circ} \mathrm{C}$ (for GAPDH), and $72^{\circ} \mathrm{C}$ for $30 \mathrm{~s}$, and 50 cycles of $95^{\circ} \mathrm{C}$ for $30 \mathrm{~s}, 55^{\circ} \mathrm{C}$ (for HVEM) or $50^{\circ} \mathrm{C}$ (for LIGHT) for $1 \mathrm{~min}$, and $72^{\circ} \mathrm{C}$ for $30 \mathrm{~s}$. A melting curve was obtained for LT $\beta$ R PCR product after each run to confirm that the signal corresponded to a unique amplicon of the predicted size. Because beacon and Taqman were used for LIGHT and HVEM PCR, respectively, the resulting signal was taken as the specific product.

Standard curves were generated in every 96-well plate for every realtime PCR run by using serial threefold dilutions of a reverse transcribed RNA from a thymus of CD-1 mouse embryo. All values obtained were normalized to GAPDH. Three separate dissections were performed for each age, and each sample was run in triplicate.

Neuron cultures. Dissociated cultures of nodose neurons were established from CD1 wild-type mice or from LIGHT ${ }^{+/+}$and $L I G H T^{-1-}$ C57BL/6 littermates. Neurons were plated in defined, serum-free medium (Ham's F-14 containing 0.25\% Albumax, Invitrogen), on a polyornithine/laminin substratum in $35 \mathrm{~mm}$ tissue culture dishes (Davies et al., 1993). All animal work was approved by Cardiff University Ethical Review Board for Animal Research and performed under the 1986 Animal Procedures Act with personal and project licenses granted by the Home Office, UK.

Ballistic transfection of dissociated neurons was performed using a hand-held gene gun (Helios Gene-gun, Bio-Rad) as previously described (Gutierrez et al., 2005). After transfection, $2 \mathrm{ml}$ of defined medium with $10 \mathrm{ng} / \mathrm{ml}$ BDNF was added to the cells. Neuron survival was quantified as previously described (Gutierrez et al., 2005). The neurite arbors of transfected neurons were visualized by expression of yellow fluorescent protein (YFP). In nontransfection experiments, neurite arbors were labeled with the fluorescent dye calcein-AM (Invitrogen) at the end of the experiment. For every condition in each experiment, images of at least 50 neurons were digitally acquired by confocal microscopy and were analyzed to obtain total neurite length, number of branch points and Sholl profiles as previously described (Gutierrez and Davies, 2007). Pairwise comparisons were made using Student's $t$ test. For multiple comparisons, ANOVA was carried out, followed by Fisher's post hoc test.

Immunocytochemistry. Cultured neurons were fixed in ice-cold methanol for $10 \mathrm{~min}$, washed three times with phosphate-buffered saline (PBS) and blocked with 5\% BSA in PBS for $1 \mathrm{~h}$ at room temperature. The cells were incubated overnight at $4^{\circ} \mathrm{C}$ with primary antibody in $1 \% \mathrm{BSA}$ (anti- $\beta$-III tubulin, 1:1000, Promega; anti-LIGHT, anti-HVEM and antiLT $\beta$ R, 1:50 Santa Cruz). After three washes, the cells were incubated with Alexa-Fluor-labeled secondary antibody (Invitrogen, 1:500) for $1 \mathrm{~h}$. All cultures were counterstained with DAPI (Chemicon). Controls (secondary antibody alone) were included in all studies.

Immunohistochemistry. Nodose ganglia and SCG were dissected from neonatal pups and fixed in formalin for $2 \mathrm{~h}$ followed by cryoprotection in $10 \%$ sucrose and embedding in OCT before being frozen and serially sectioned at $20 \mu \mathrm{m}$. The sections were immunostained on glass slides as described above and examined by confocal microscopy. To compare the levels of LIGHT and its receptors in the nodose ganglion, vagus nerve and SCG, these structures were sectioned together in the same block and were mounted side by side on the same slides for immunostaining.

Quantification of NF- $\kappa$ B activity. The relative level of NF- $\kappa$ B activation was estimated by transfecting neurons with a plasmid that expresses GFP under the control of an NF- $\kappa$ B promoter as described previously (Gutierrez et al., 2005). Between 40 and 60 neurons were imaged for each experimental condition and all imaging and quantification was performed blind. Statistical comparisons were performed using simple ANOVA followed by Fisher's post hoc test.

\section{Results}

\section{Expression of LIGHT and its receptors, LT $\beta$ R and HVEM, in developing neurons}

To identify novel candidate members of the TNFSF involved in neuronal development, we carried a real-time PCR screen for expression of all TNFSF and TNFRSF members in three extensively studied, experimentally tractable populations of peripheral nervous system neurons of developing mice and in several CNS regions. This screen revealed distinctive patterns of expression of transcripts for LIGHT and its receptors LT $\beta$ R and HVEM in the nodose ganglia, trigeminal ganglia and superior cervical ganglia (SCG) and in the hippocampus and frontal cortex of newborn (P0) mice (Fig. 1A). Whereas the levels of LIGHT mRNA relative to the housekeeping GAPDH mRNA in peripheral ganglia were not significantly different, the levels of LT $\beta$ R mRNA and HVEM mRNA relative to GAPDH mRNA were significantly higher in nodose ganglia compared with other ganglia. Immunohistochemical localization of LIGHT, LT $\beta$ R and HVEM in sections of the nodose ganglia and SCG confirmed expression of these proteins and, in accordance with the observed differences in the expression of HVEM and LT $\beta$ R mRNAs between these ganglia, revealed noticeably more intense HVEM and LT $\beta$ R immunoreactivity in nodose ganglia (Fig. $1 B$ ). The vagus nerve on which the nodose ganglion is located and which contains the axons of nodose neurons also displayed clear immunoreactivity for LIGHT, LT $\beta$ R and HVEM (Fig. $1 B$ ). It is worth noting that the rostral pole of the P0 nodose ganglion contains a group of neurons that belongs to the much smaller petrosal ganglion that fuses with the nodose ganglion earlier in development. Immunohistochemical staining performed on sections passing through this region revealed no differences in immunoreactivity for LIGHT, LT $\beta$ R and HVEM between nodose and petrosal neurons (data not shown).

Whereas examination of high-power images of the above immunohistochemical preparations of the nodose ganglion and vagus nerve indicated expression of LIGHT, LT $\beta$ R and HVEM in the cell bodies and processes of neurons, we used immunocytochemistry to confirm the cellular distribution of these proteins in dissociated cell cultures established from the nodose ganglia of newborn mice. These studies revealed that the cell bodies and processes of all neurons in these cultures (positively identified with anti- $\beta$ III tubulin antibodies) were labeled by specific antibodies to LIGHT, HVEM and LT $\beta$ R, and that none of the nonneuronal cells were labeled by these antibodies (Fig. 1C). No cells were labeled when primary antibodies were omitted from either 
A
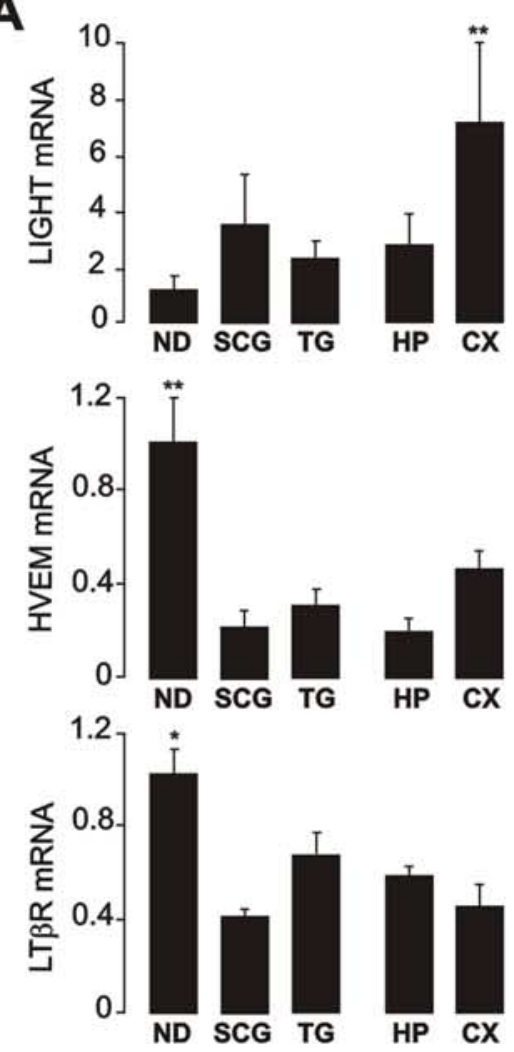

B

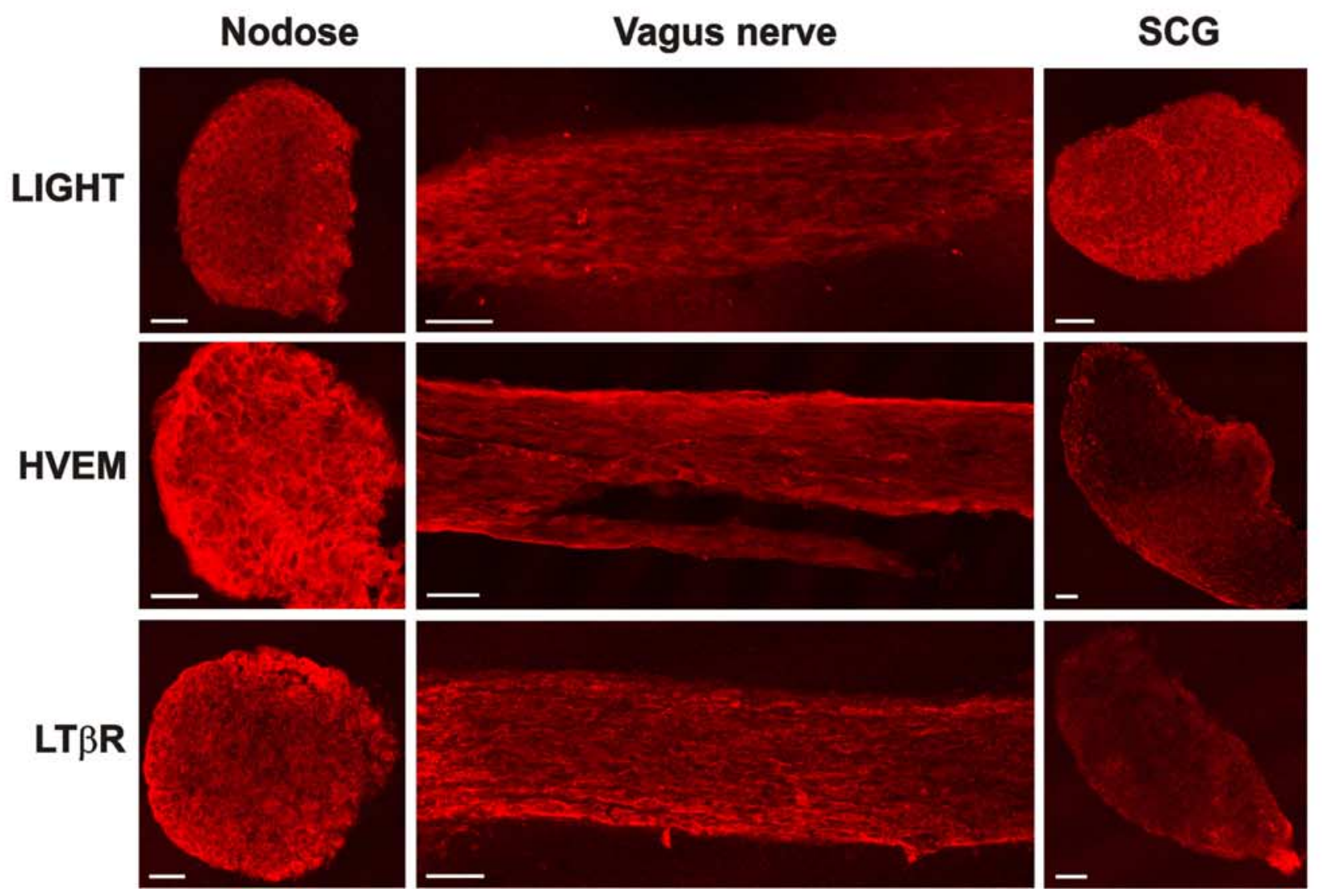

C
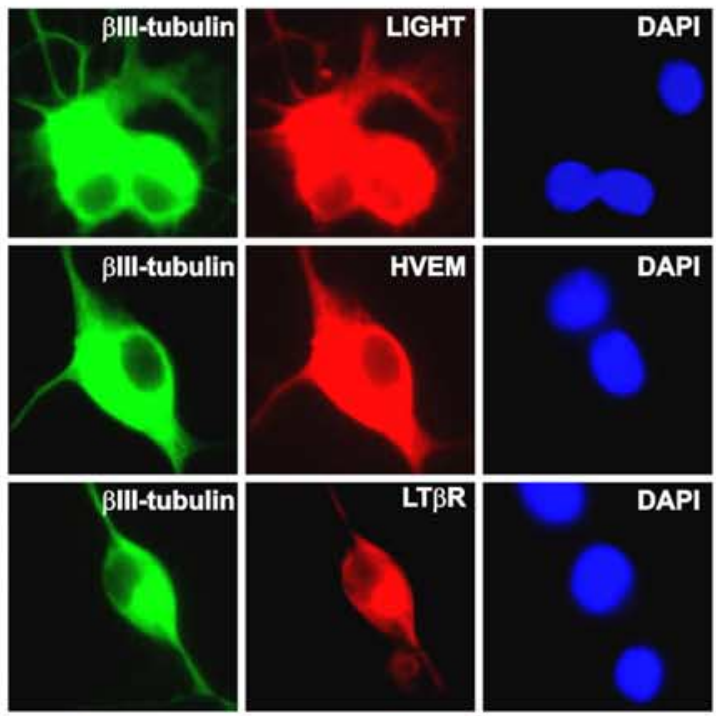

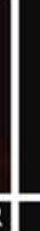
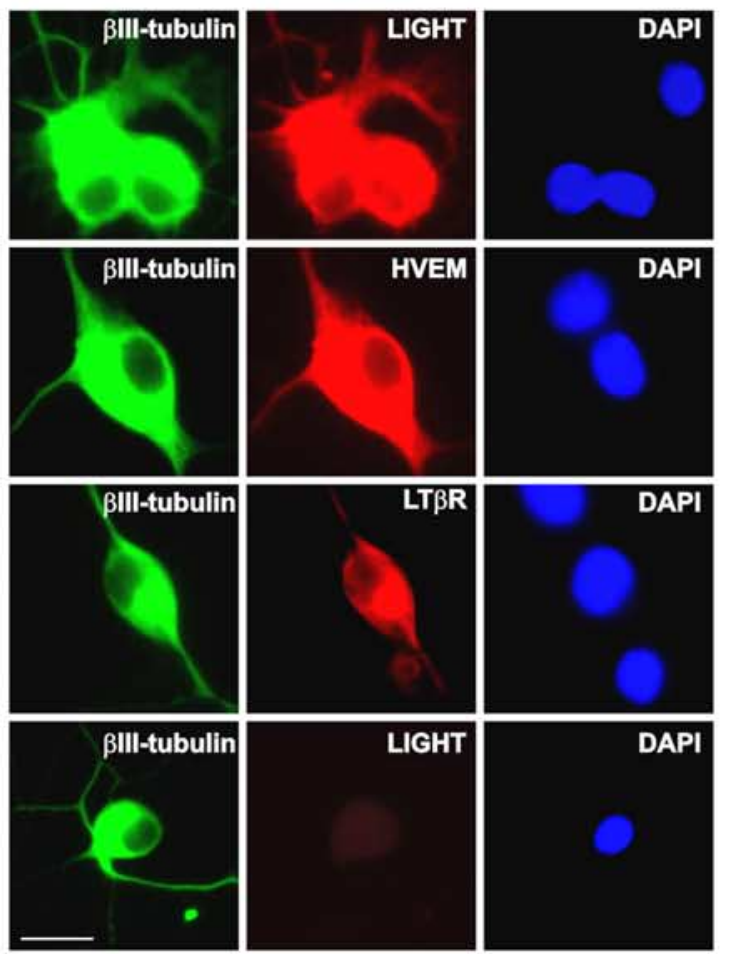

DAPI
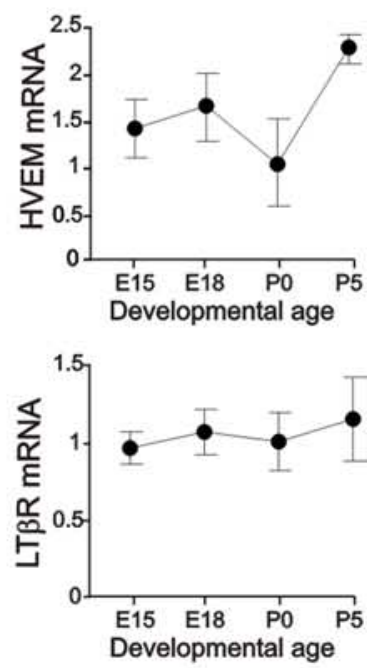

SCG

Figure 1. LIGHT, HVEM, and LT $\beta$ R are differentially expressed in the developing nervous system. $A$, Quantification of the relative levels of LIGHT, HVEM, and LT $\beta R$ mRNAs in total RNA extracted from nodose ganglia (ND), superior cervical ganglia (SCG), trigeminal ganglia (TG), hippocampus (HP), and cortex (CX) of P0 mice by real-time PCR. The levels of these mRNAs were calculated relative to GAPDH mRNA and normalized to a value of 1.0 for the nodose data. Means \pm SEM of assays performed on RNA extracted from three separate sets of tissue, $\left({ }^{*} p<0.05\right.$ and ${ }^{* *} p<0.01$ indicate statistically significant difference between the indicated bar and all other bars). $\boldsymbol{B}$, Immunohistochemical localization and relative levels of expression of LIGHT, HVEM, and LT $\beta R$ in sections of PO nodose ganglia, vagus nerve, and SCG. Scale bars, $50 \mu \mathrm{m}$. C, Photomicrographs of representative fields of dissociated cultures of P0 nodose neurons that were (Figure legend continues.) 
the immunohistochemical or immunocytochemical protocols (data not shown), and nodose neurons cultured from LIGHTdeficient newborn mice were not labeled by the anti-LIGHT antibody (Fig. 1C). The selective expression of LIGHT, HVEM and LT $\beta \mathrm{R}$ in all nodose neurons suggests that each neuron coexpresses LIGHT and its receptors. Real time PCR revealed that the levels of LIGHT, HVEM and LT $\beta$ R mRNAs remained fairly constant, relative to GAPDH mRNA, from E15 to P5 in nodose ganglia (Fig. 1D).

\section{LIGHT overexpression impairs BDNF-promoted neurite growth from nodose neurons}

Given the relatively high levels of expression of the LIGHT receptors HVEM and LT $\beta$ R in developing nodose neurons, we began investigating the functions of LIGHT signaling by transfecting these cells with a LIGHT expression plasmid to examine the consequences of enhancing LIGHT signaling. P0 nodose neurons were transfected with either a LIGHT expression plasmid or an empty control pcDNA3.1 plasmid $2 \mathrm{~h}$ after plating, and the survival of the transfected neurons together with the size and complexity of their neurite arbors were quantified after $24 \mathrm{~h}$ incubation in medium containing BDNF. More than $80 \%$ of transfected neurons were surviving at this time, and there was no significant difference in the number of LIGHT overexpressing neurons and control transfected neurons (supplemental Fig. $1 A$, available at www.jneurosci.org as supplemental material). Although LIGHT overexpression had no effect on neuronal survival in the presence of BDNF, it caused a marked, highly significant reduction on the number of branch points (Control: $39 \pm 2$; LIGHT: $22 \pm 2$ ) and neurite arbor length (Control: $2794 \pm 112 \mu \mathrm{m}$; LIGHT: $1459 \pm$ $131 \mu \mathrm{m})$. Sholl analysis, which provides a graphic representation of branching with distance from the cell body, showed that the neurite arbors of LIGHT-overexpressing neurons were much smaller and less complex than those of control transfected neurons (Fig. $2 \mathrm{~A}$ ). The typical appearance of LIGHT-transfected and control-transfected neurons is shown in Figure $2 B$.

To determine whether the inhibitory effect of LIGHT overexpression on BDNF-promoted neurite growth is restricted to a particular phase of development, we performed transfection experiments on cultured nodose neurons obtained from mouse embryos and neonates of different ages. Quantification of neurite length (Fig. 2C) and branch point number (Fig. 2D) $24 \mathrm{~h}$ after transfection revealed that LIGHT overexpression had no significant effect on neurite size and complexity in E16 and P3 cultures, but caused highly significant reductions in length and branching in E18 and P0 cultures that were greatest at P0 (44\% and 48\% lower than in control-transfected neurons, respectively) These results demonstrate that the effect of LIGHT overexpression on neurite growth is restricted to the immediate perinatal period, and rule out any nonspecific detrimental effects of LIGHT overexpression on neurite growth (because no decreases were observed before and after this period of development).

\footnotetext{
(Figure legend continued.) cultured for $24 \mathrm{~h}$ in medium containing $10 \mathrm{ng} / \mathrm{ml}$ BDNF before being triple labeled with either anti- $\beta$-III tubulin, anti-LIGHT, and DAPI (top row), anti- $\beta$-III tubulin, anti-HVEM, and DAPI (second row), or anti- $\beta$-III tubulin, anti-LT $\beta R$, and DAPI (third row). The lower row shows a representative nodose neuron cultured from a PO LIGHT-deficient mouse stained for anti- $\beta$-III tubulin, anti-LIGHT, and DAPI. Scale bar, $50 \mu \mathrm{m}$. D, Quantification of the relative levels of LIGHT, HVEM, and LT $\beta$ R mRNAs in total RNA extracted from nodose ganglia of $\mathrm{E} 15, \mathrm{E} 18, \mathrm{P0}$, and $\mathrm{P} 5$ mice by real-time PCR. The levels of these mRNAs were calculated relative to GAPDH mRNA and normalized to a value of 1.0 at the $P 0$ age point (mean \pm SEM of assays performed on RNA extracted from three separate sets of ganglia at each age).
}

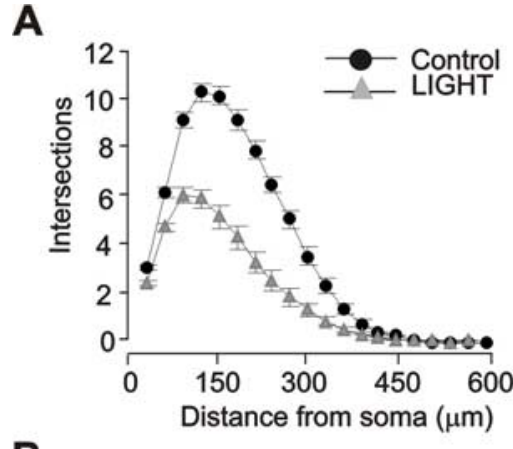

B
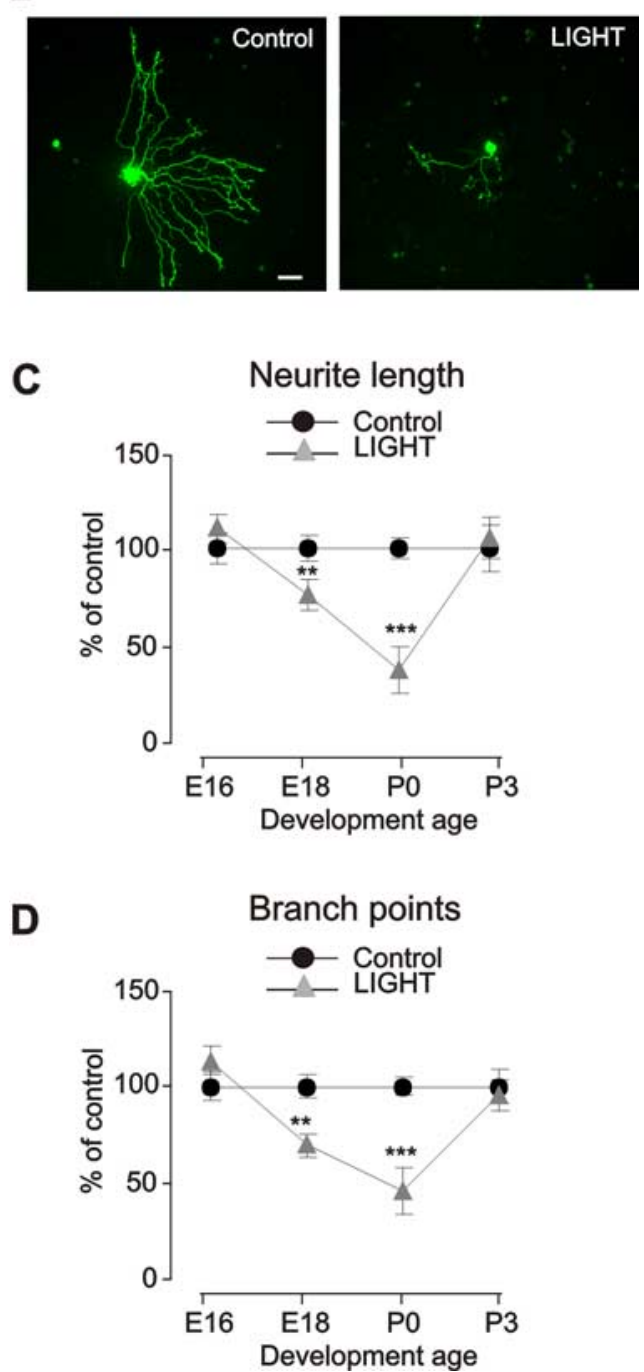

Figure 2. $\quad \boldsymbol{A}-\boldsymbol{D}, \mathrm{LIGHT}$ overexpression impairs BDNF-promoted neurite growth from nodose neurons during a developmental window. Dissociated cultures of $P 0$ nodose neurons were transfected $3 \mathrm{~h}$ after plating with a YFP expression plasmid together with either a LIGHT expression plasmid (LIGHT) or an empty control plasmid (control). After a further $24 \mathrm{~h}$ incubation in medium containing BDNF $(10 \mathrm{ng} / \mathrm{ml})$, confocal images of neurite arbors were acquired for Sholl analysis $(\boldsymbol{A})$. Representative control-transfected and LIGHT-overexpressing neurons are shown in $\boldsymbol{B}$ (Scale bar, $50 \mu \mathrm{m}$ ). $\boldsymbol{C}, \boldsymbol{D}$, Nodose neurons from E16, E18, P0, and P3 mice were transfected and cultured as described for $\boldsymbol{A}$, and $\boldsymbol{B}$ above. Total neurite length $(\boldsymbol{C})$ and number of branch points $(\boldsymbol{D})$ were determined $24 \mathrm{~h}$ after transfection, and control data were normalized to $100 \%$ at each age to facilitate comparison of the effects of LIGHT overexpression at different ages. The combined results of 10 separate experiments at each age are plotted (means and SEs of the data from $>500$ neurons for each data point). Statistically significant difference with controltransfected neurons: ${ }^{* *} p<0.01,{ }^{* * *} p<0.001$. 
Although neonatal SCG neurons express much lower levels of HVEM and LT $\beta$ R than nodose neurons, we also tested the effects of overexpressing LIGHT in these neurons. This had no significant effect on either number of branching points (controltransfected neurons, $16 \pm 1$; LIGHT-overexpressing neurons, $14 \pm 1$ ) or total neurite length (control-transfected neurons, $1760 \pm 123 \mu \mathrm{m}$; LIGHT-overexpressing neurons, $1894 \pm 199$ $\mu \mathrm{m})$. Accordingly, Sholl profiles of control-transfected neurons and LIGHT-overexpressing neurons were not significantly different (data not shown).

\section{HVEM mediates the effect of LIGHT on BDNF-promoted neurite growth from nodose neurons}

To determine which of the two coexpressed LIGHT receptors mediate the neurite growth inhibitory effect of LIGHT, we transfected P0 nodose neurons with plasmids that express LIGHT mutants that selectively activate either LT $\beta$ R or HVEM. LIGHT$\mathrm{R} 228 \mathrm{E}$ has an arginine to glutamic acid substitution at amino acid 228 that causes it to selectively bind and activate LT $\beta$ R (Chen et al., 2003), whereas LIGHT-G119E has glycine to glutamic acid substitution at amino acid 119 that causes it to selectively bind and activate HVEM (Rooney et al., 2000). Neurons expressing the LIGHT-R228E mutant had neurite arbors that were not significant different from those of control-transfected neurons in terms of overall length (Fig. 3A) or Sholl profiles (Fig. 3B) after $24 \mathrm{~h}$ incubation with BDNF, suggesting that LT $\beta$ R does not mediate the neurite growth inhibitory effects of LIGHT. In contrast, expression of the LIGHT-G119E mutant caused highly significant reductions in neurite length and complexity (Fig. $3 A, B$ ), suggesting that HVEM mediates the neurite growth inhibitory effects of LIGHT. Neither LIGHT-G119E nor LIGHT-R228E had an effect on cell survival (supplemental Fig. $1 B$, available at www.jneurosci.org as supplemental material).

To provide supporting evidence for the requirement of HVEM in mediating the neurite growth inhibitory effect of LIGHT, we tested whether an anti-HVEM function-blocking antibody interferes with the neurite growth inhibitory effect of overexpressing LIGHT. P0 nodose neurons were transfected with the LIGHT plasmid and were incubated with BDNF for $24 \mathrm{~h}$ in the presence and absence of anti-HVEM. The length and complexity of the neurite arbors of LIGHT-overexpressing neurons treated with the anti-HVEM antibody were significantly greater than LIGHT-overexpressing neurons not treated with this antibody (Fig. 3C,D), reinforcing the importance of HVEM in mediating the neurite growth inhibitory effect of LIGHT.

\section{Endogenous HVEM signaling exerts a neurite growth inhibitory effect on nodose neurons}

Our demonstration that enhancing LIGHT-HVEM signaling in neonatal nodose neurons inhibits BDNF-promoted neurite growth begged the question whether endogenous LIGHTHVEM signaling exerts an inhibitory influence on the growth of neurites from these neurons. To investigate this, we cultured P0 nodose neurons with and without the function-blocking antiHVEM antibody for $24 \mathrm{~h}$ in the presence of different concentrations of BDNF and in the absence of this neurotrophin. To prevent the death of neurons grown without BDNF or in suboptimal concentrations of BDNF, the broad-spectrum, irreversible caspase inhibitor Boc-D-FMK was added to all cultures. Neurons treated with the anti-HVEM antibody had significantly longer, more complex neurite arbors than untreated neurons in both the absence of BDNF and in the presence of BDNF at the subsaturating concentrations of 0.1 and $1 \mathrm{ng} / \mathrm{ml}$ (Fig. 4). Anti-HVEM did
A
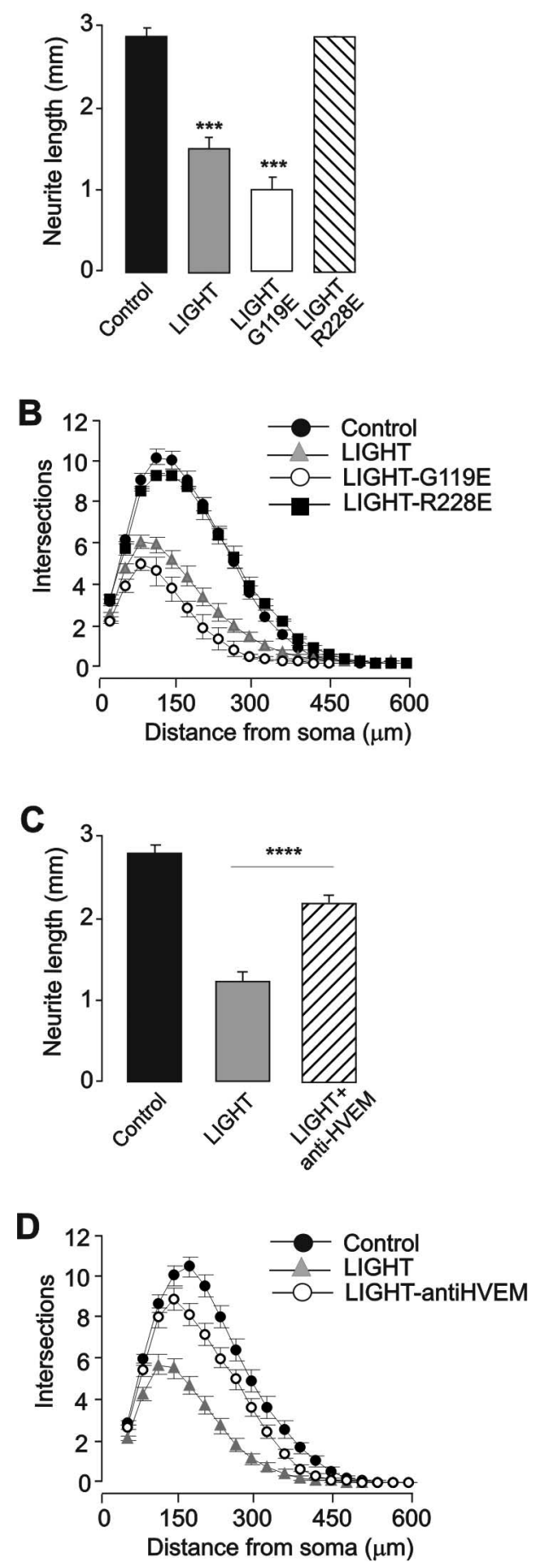

Figure 3. HVEM mediates the inhibitory effect of LIGHT on BDNF-promoted neurite growth from nodose neurons. $\boldsymbol{A}, \boldsymbol{B}$, Dissociated cultures of $\mathrm{P} 0$ nodose neurons were transfected $3 \mathrm{~h}$ after plating with a YFP expression plasmid together with a plasmid expressing either LIGHT, LIGHTR228E, or LIGHT-G119E or with an empty control plasmid (control). After a further $24 \mathrm{~h}$ incubation in medium containing BDNF (10 ng/ml), confocal images of neurite arbors were acquired for calculation of total neurite length $(\boldsymbol{A})$ and Sholl analysis $(\boldsymbol{B}) . \boldsymbol{C}, \boldsymbol{D}$, Dissociated cultures of PO nodose neurons were transfected $3 \mathrm{~h}$ after plating with a YFP expression plasmid together with either a LIGHT expression plasmid or an empty control plasmid. After a further $24 \mathrm{~h}$ incubation in medium containing BDNF (10 ng/ml) with and without anti-HVEM blocking antibody (1:50), confocal images of neurite arbors were acquired for calculation of total neurite length $(\boldsymbol{C})$ and Sholl analysis $(\boldsymbol{D})$. The combined data from three separate experiments of each kind are plotted (means and SEs of the data from $>150$ neurons for each data point). Statistically significant difference with control-transfected neurons: ${ }^{* * *} p<0.001(\boldsymbol{A})$. Statistically significant difference with LIGHT-transfected neurons: ${ }^{* * *} p<0.0001(\boldsymbol{C})$. 
A

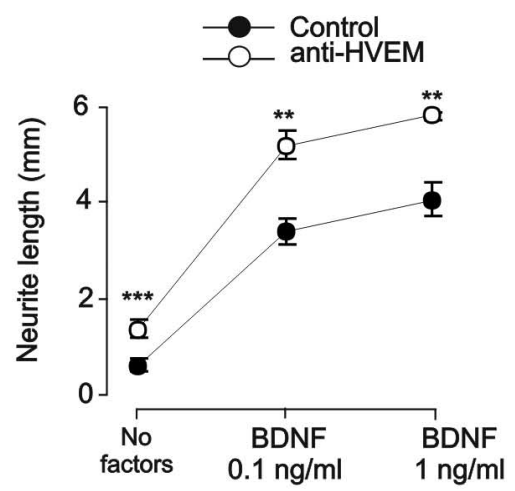

B
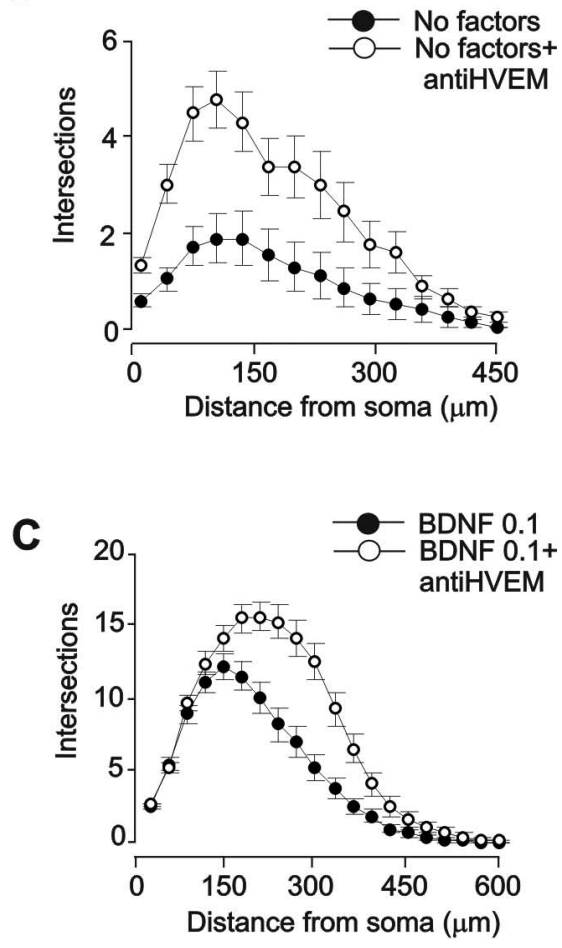

D

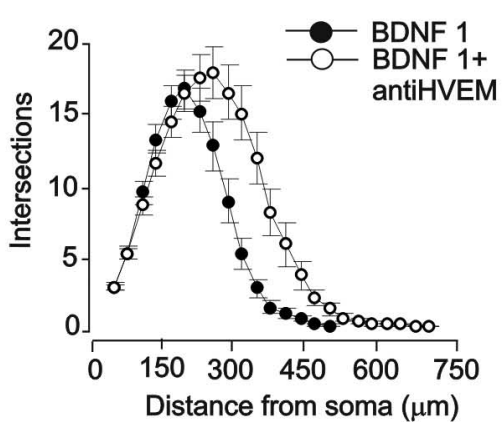

Figure 4. $\boldsymbol{A}-\boldsymbol{D}$, Endogenous HVEM signaling exerts a neurite growth inhibitory effect on nodose neurons. Dissociated cultures of $\mathrm{PO}$ nodose neurons were incubated with and without anti-HVEM blocking antibody (1:50) in medium containing the caspase inhibitor Boc-D-FMK (25 $\mu \mathrm{m})$ and either no BDNF, $0.1 \mathrm{ng} / \mathrm{ml}$ BDNF, or $1 \mathrm{ng} / \mathrm{ml}$ BDNF. After $24 \mathrm{~h}$ incubation the neurons were labeled with calcein-AM and confocal images of neurite arbors were acquired for calculation of total neurite length $(\boldsymbol{A})$ and Sholl analysis $(\boldsymbol{B}-\boldsymbol{D})$. The combined data from three separate experiments of each kind are plotted (means and SEs of the data from $>150$ neurons for each data point). Statistically significant differences in neurite length in cultures with and without anti-HVEM: ${ }^{* *} p<0.01,{ }^{* * *} p<0.001$. not, however, significantly increase the Sholl profiles of neurons grown with the saturating BDNF concentration of $10 \mathrm{ng} / \mathrm{ml}$ (data not shown). There were no significant differences in the numbers of neurons surviving under all conditions in these experiments (supplemental Fig. 1C, available at www.jneurosci.org as supplemental material). Together, these results suggest that endogenous HVEM signaling exerts an inhibitory effect on neurite growth where the concentration of BDNF is limiting.

\section{LIGHT-deficient neurons exhibit enhanced neurite growth} in culture

To investigate further the significance of endogenous LIGHTHVEM signaling in regulating neurite growth, we established dissociated cultures nodose neurons from LIGHT-deficient newborn mice and wild-type littermates. For these experiments, LIGHT $^{+/-}$mice were crossed to generate $\mathrm{LIGHT}^{+/+}$and $L I G H T^{-l-}$ pups. Separate nodose neuron cultures were established from each newborn pup, and neuronal survival and neurite arbor size and complexity were quantified after $24 \mathrm{~h}$ incubation with and without BDNF at concentrations of $0.1 \mathrm{ng} / \mathrm{ml}$ and $1 \mathrm{ng} / \mathrm{ml}$. These data were obtained before the genotypes of the pups were determined to avoid any possible observe bias. All cultures received the caspase inhibitor Boc-D-FMK to prevent the death of neurons grown with suboptimal levels of BDNF and without this neurotrophin. Neuron counts confirmed that there were no significant differences in neuronal survival between wild- type and LIGHT-deficient neurons in all experimental conditions after $24 \mathrm{~h}$ incubation (supplemental Fig. $1 \mathrm{D}$, available at www.jneurosci.org as supplemental material). The neurite arbors of LIGHT-deficient neurons were significantly longer and more branched than those of wild-type neurons in both the presence and absence of BDNF (Fig. 5). As was the case with the antiHVEM antibody experiments, the effects of LIGHT deficiency on neurite growth were proportionately greater in cultures lacking BDNF. These results show that endogenously synthesized LIGHT exerts an inhibitory effect on neurite growth from the nodose neurons of newborn mice that is especially pronounced in the absence of BDNF or low BDNF concentrations.

\section{LIGHT inhibits neurite growth by inhibiting NF- $\kappa$ B signaling} in nodose neurons

Recent work has shown that NF- $\kappa \mathrm{B}$ signaling makes an important contribution to BDNF-promoted neurite growth and is essential for CNTF-promoted neurite growth from newborn mouse nodose neurons (Gutierrez et al., 2005, 2008; Gallagher et al., 2007). Because NF- $\kappa$ B plays a major role in mediating cellular responses to members of the TNFSF (Grivennikov et al., 2006), we studied the effect of LIGHT signaling on NF- $\kappa$ B transcriptional activity in nodose neurons and tested whether this plays a role in mediating the neurite growth inhibitory effects of LIGHT. The level of NF- $\kappa$ B transcriptional activity in nodose neurons was measured by transfecting these cells with a reporter construct in which GFP expression is under the control of a $\kappa \mathrm{B}$ binding regulatory element (Gutierrez et al., 2005). The fluorescence signal from this reporter was 73\% lower in neurons cotransfected with the LIGHT expression plasmid compared with neurons cotransfected with an empty control expression plasmid (Fig. 6A). This suggests that enhancing LIGHT signaling in nodose neurons inhibits NF- $\kappa \mathrm{B}$ in these cells. To determine which receptor mediates NF- $\kappa$ B inhibition by LIGHT, we cotransfected nodose neurons with the NF- $\kappa \mathrm{B}$ reporter and either of the two receptorspecific LIGHT mutants. Whereas expression of LIGHT-G119E mutant caused a marked reduction in reporter signal (90\% lower 
A

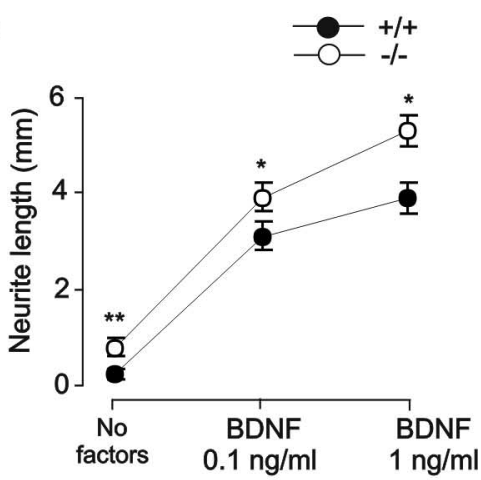

B

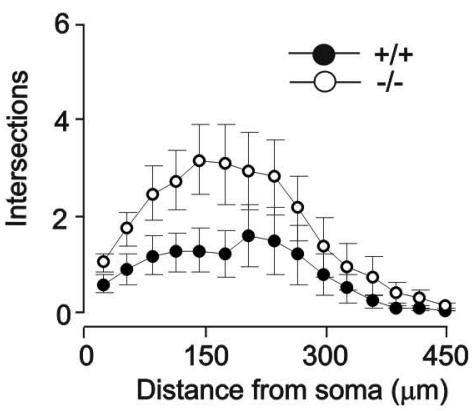

C

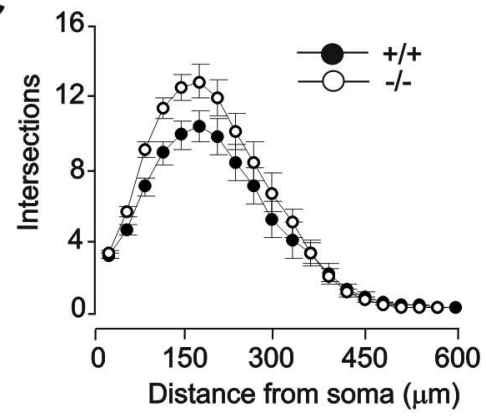

D

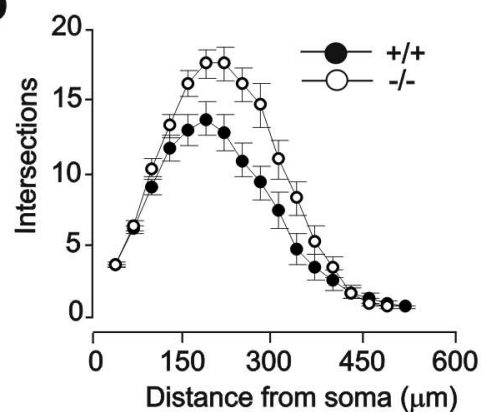

Figure 5. $A-D$, LIGHT-deficient nodose neurons exhibit enhanced neurite growth in culture. Dissociated cultures of $\mathrm{PO}$ nodose neurons were established from $\mathrm{LIGHT}^{-1-}(-/-)$ and LIGHT ${ }^{+/+}$ $(+/+)$ littermates and were incubated in medium containing either no BDNF, $0.1 \mathrm{ng} / \mathrm{ml} \mathrm{BDNF}$, or 1 $\mathrm{ng} / \mathrm{ml}$ BDNF. The medium in cultures contained the caspase inhibitor Boc-D-FMK (25 $\mu \mathrm{m})$. After $24 \mathrm{~h}$ incubation the neurons were labeled with calcein-AM and confocal images of neurite arbors were acquired for calculation of total neurite length $(\boldsymbol{A})$ and Sholl analysis $(\boldsymbol{B}-\boldsymbol{D})$. The combined data from three separate experiments of each kind are plotted (means and SEs of the data from $>150$ neurons for each data point). Statistically significant differences in neurite length between of neurons from LIGHT $^{-/-}$and LIGHT ${ }^{+/+}$mice: ${ }^{*} p<0.05,{ }^{* *} p<0.01$.

than in control transfected neurons), expression of the LIGHTR228E mutant had no effect on the reporter signal (Fig. 6A), implying that LIGHT inhibits NF- $\kappa \mathrm{B}$ in neurons by acting via HVEM. As a positive control for NF- $\kappa \mathrm{B}$ inactivation in these experiments, we cotransfected nodose neurons with the NF- $\kappa \mathrm{B}$ reporter and double stranded DNA oligonucleotides containing the $\kappa \mathrm{B}$ consensus binding sequence that compete for activated NF- $\kappa \mathrm{B}$ and prevent its binding to $\kappa \mathrm{B}$ regulatory elements (Morishita et al., 1997). As expected, this $\kappa \mathrm{B}$ decoy DNA, but not scrambled control DNA (data not shown), caused a very marked reduction in reporter signal similar to those observed in neurons overexpressing LIGHT or LIGHT-G119E (Fig. 6A).

To determine whether LIGHT-induced NF- $\kappa \mathrm{B}$ inactivation is required for the growth inhibitory effect of LIGHT, we cotransfected nodose neurons with the LIGHT-G119E plasmid together with plasmids expressing the p65 and p50 NF- $\kappa \mathrm{B}$ subunits to enhance NF- $\kappa \mathrm{B}$ transcriptional activity (Gutierrez et al., 2008) and counter LIGHT-induced NF- $\kappa$ B inactivation. As expected, the NF- $\kappa$ B reporter signal in LIGHT-G119E expressing neurons overexpressing p 65 and p50 was significantly greater than in control transfected neurons (Fig. 6A). Finally, to determine whether this reversal in NF- $\kappa$ B transcriptional activity prevented LIGHTinduced neurite growth inhibition, we compared the size and complexity of the neurite arbors of neurons transfected with the LIGHT-G119E plasmid and neurons transfected with this plasmid in combination with p65 and p50 plasmids. After $24 \mathrm{~h} \mathrm{incu-}$ bation in medium containing BDNF, there were no significant differences in the size and complexity of the neurite arbors of control-transfected neurons and neurons transfected with the LIGHT-G119E plasmid in combination with p65 and p50 plasmids (Fig. $6 B, C$ ), indicating that overexpression of p65 and p50 completely prevented the neurite growth inhibitory effect of LIGHT-G119E. Representative examples of control-transfected neurons and neurons expressing LIGHT-G119E alone or in combination with overexpressed $\mathrm{p} 65$ and $\mathrm{p} 50$ are shown in Figure $6 D$. Together, these results demonstrate that LIGHT inactivates NF- $\kappa$ B signaling by an HVEM-dependent mechanism, and that this inhibition is required for the neurite growth inhibitory effects of LIGHT.

\section{Discussion}

We have discovered that LIGHT, a member of the TNFSF with no previously described function in the nervous system, acting via its receptor HVEM is a potent negative regulator of neurite growth from neonatal nodose ganglion neurons. These neurons coexpress LIGHT and both its signaling receptors HVEM and LT $\beta$ R during the period of development when the axons of these neurons are ramifying in their peripheral and central targets. Overexpression of LIGHT in cultured nodose neurons markedly inhibits the neurite growth-promoting effects of saturating levels of BDNF during a narrow developmental window in the immediate perinatal period. Enhancing HVEM signaling in these neurons by expressing a LIGHT mutant that selectively activates HVEM likewise markedly inhibits BDNF-promoted neurite growth. In contrast, expression of a LIGHT mutant that selectively activates LT $\beta$ R has no effect on neurite growth, and neither this mutant nor the HVEM-selective LIGHT mutant have any effect on neuronal survival with or without BDNF. Blocking endogenous ligand-dependent activation of HVEM in cultured nodose neurons using a function-blocking anti-HVEM antibody enhances the low level of neurite growth that occurs in the absence of BDNF and enhances neurite growth from neurons cultured with subsaturating, but not saturating, levels of BDNF. Likewise, LIGHT-deficient neurons have significantly larger, more branched neurite arbors than those of wild-type mice in the presence and absence of subsaturating levels of BDNF. Together, these findings indicate that LIGHT-HVEM signaling and BDNF- 
TrkB signaling exert opposing actions on neurite growth from perinatal nodose neurons, and that the size and complexity of the neurite arbors of these neurons is governed by the relative levels of signaling in these two ligand-receptor systems.

Whereas nodose neurons obtain BDNF from target field cells in vivo, the coexpression of LIGHT and HVEM in nodose neurons suggests that LIGHT-HVEM signaling is activated by either an autocrine mechanism within individual neurons or by a paracrine mechanism between neurons. Whether acting by autocrine or paracrine mechanisms, the basal level of LIGHT-HVEM signaling in nodose neurons could play a role in reducing or restricting terminal axon growth and branching from neurons that are less successful in the competition for targetderived BDNF in vivo. In this way, LIGHTHVEM signaling may be involved in facilitating the elimination of superfluous or inappropriate axon terminals during the later stages of target field innervation. The presence of LIGHT and HVEM in the intact vagus nerve and along the neurites of cultured nodose neurons raises the possibility that LIGHT-HVEM interaction could occur between the distal branches of sensory axons. In addition to autocrine and/or paracrine activation of HVEM by LIGHT on developing sensory axons, it is possible that LIGHT produced by a variety of other cell types could play a role in the local regulation of axonal growth and branching in vivo. Likewise, although our finding that anti-HVEM does not enhance neurite growth from LIGHT-deficient nodose neurons (data not shown) suggests that LIGHT is the only functionally relevant HVEM ligand in our in vitro paradigm, this does not preclude the possibility that LT- $\alpha 3$, the other TNFSF ligand for HVEM, may act on nodose neurons in vivo. Our demonstration that LIGHT and HVEM are also expressed in at least two other peripheral ganglia and in the developing hippocampus and cortex raises the possibility that HVEM may play a role in regulating the growth of neural processes elsewhere in the nervous system. Although preliminary studies in neonatal SCG neurons, which express much lower levels of HVEM than nodose neurons, have not provided evidence for a role for LIGHT in regulating neurite growth from these neurons, our positive data from extensive studies of nodose neurons set the president for exploring the role of HVEM and its ligands in regulating the growth of neural processes elsewhere in the nervous system.

We have demonstrated that enhanced LIGHT-HVEM signaling potently inhibits NF- $\kappa \mathrm{B}$ signaling in neonatal nodose neurons. This finding contrasts with numerous previous studies in a

B neurons.

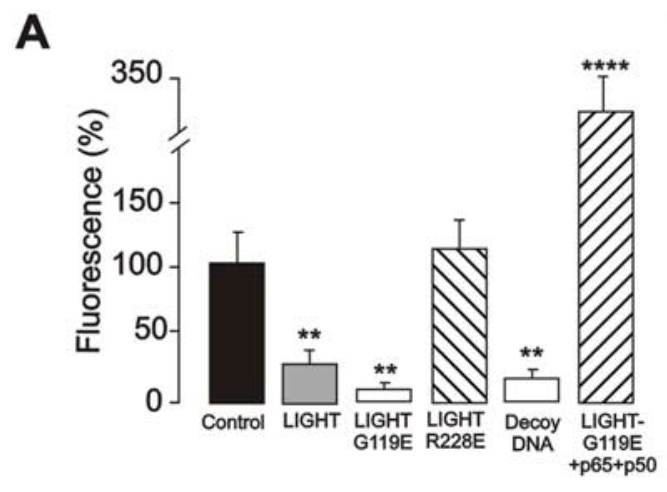

D
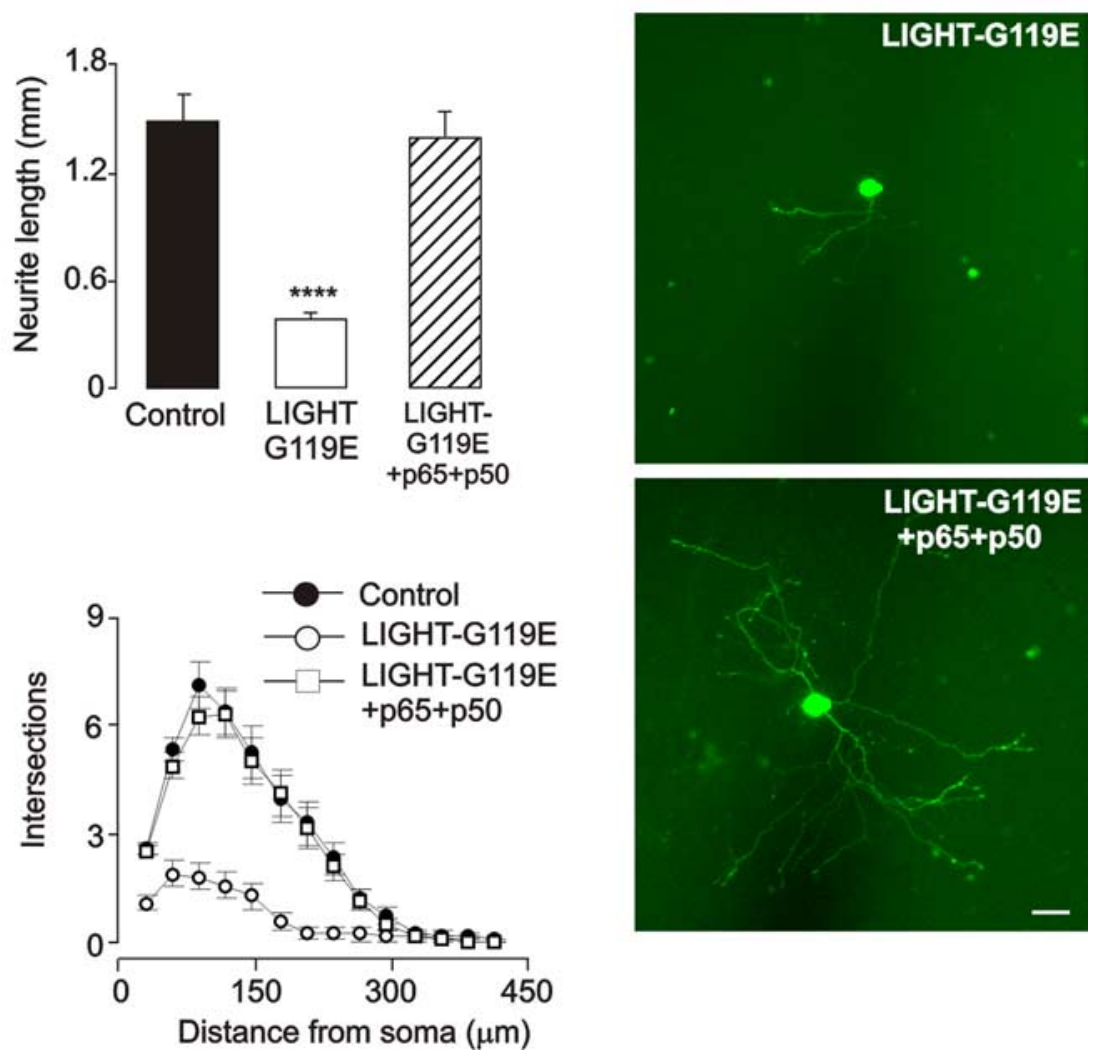

Figure 6. LIGHT inhibits neurite growth by inhibiting NF- $\kappa B$ signaling in nodose neurons. $A$, Dissociated cultures of $P 0$ nodose neurons were transfected $3 \mathrm{~h}$ after plating with an RFP plasmid and the $\kappa B$-GFP reporter together with either the LIGHT plasmid, LIGHT-G119E plasmid, LIGHT-R228E plasmid, LIGHT-G119E, p65, and p50 plasmids in combination, an empty control plasmid (control), or $\kappa B$ decoy DNA. After a further $18 \mathrm{~h}$ incubation in medium containing BDNF $(10 \mathrm{ng} / \mathrm{ml})$ the intensity of the GFP reporter signal was quantified in transfected neurons (positively identified by RFP fluorescence). $\boldsymbol{B}-\boldsymbol{D}$, Dissociated cultures of $P 0$ nodose neurons were transfected $3 \mathrm{~h}$ after plating with a YFP plasmid together with the LIGHT-G119E plasmid, the LIGHT-G119E, p65, and p50 plasmids in combination, or an empty control plasmid. After a further $24 \mathrm{~h}$ incubation in medium containing BDNF $(10 \mathrm{ng} / \mathrm{ml})$, confocal images of neurite arbors were acquired for calculation of total neurite length $(\boldsymbol{B})$ and Sholl analysis $(\boldsymbol{C})$. D, Photomicrographs of a representative control-transfected neuron, a LIGHT-G119E expressing neuron, and a LIGHT-G119E expressing neuron in which p65 and p50 are overexpressed (Scale bar, $50 \mu \mathrm{m}$ ). The combined data from three separate experiments of each kind are plotted. Statistically significant differences with controls: ${ }^{* *} p<0.01,{ }^{* * *} p<0.0001$ compared with control transfected

wide variety of cell types that have reported that LIGHT, acting via either HVEM or LT $\beta$ R, activates NF- $\kappa$ B (Marsters et al., 1997; Hikichi et al., 2001; Matsui et al., 2002; Zou and Hu, 2005; Wei et al., 2006; Pierer et al., 2007). We have previously shown that $\mathrm{NF}-\kappa \mathrm{B}$ is a key regulator of neurite growth in neonatal nodose neurons, and that inhibiting canonical NF- $\kappa \mathrm{B}$ signaling in these neurons significantly reduces BDNF-promoted neurite growth during a developmental window from E18 to P1 (Gutierrez et al., 
2005). Interestingly, the inhibitory effect of LIGHT overexpression on BDNF-promoted neurite growth is restricted to a similar developmental window. Our demonstration that circumventing LIGHT-induced NF- $\kappa$ B inactivation by overexpressing the p50 and p $65 \mathrm{NF}-\kappa \mathrm{B}$ subunits during this window completely prevents LIGHT-induced neurite growth inhibition, suggests that LIGHT-induced NF- $\kappa$ B inactivation is the mechanism by which LIGHT negatively regulates BDNF-promoted neurite growth. Together, these observations suggest that the developmental window over which LIGHT inhibits neurite growth is governed by the developmentally restricted requirement for NF- $\kappa \mathrm{B}$ signaling in neurite growth rather than by developmental changes in the expression of LIGHT and/or HVEM.

Several recent reports have implicated members of the TNFSF and their receptors in neurite growth regulation. FasL promotes neurite growth from DRG explants (Desbarats et al., 2003) and increases neurite branching from cultured hippocampal and cortical neurons (Zuliani et al., 2006). FN14 overexpression enhances neurite growth from in PC12 cells (Tanabe et al., 2003). TNF $\alpha$ inhibits neurite growth from hippocampal neurons in culture (Neumann et al., 2002), but paradoxically the dendritic arbors of these neurons are smaller in TNF $\alpha$-deficient mice in vivo (Golan et al., 2004). TROY can substitute for p75NTR in the Nogo receptor complex that mediates the effects of myelinassociated neurite growth inhibitory factors (Shao et al., 2005). Most recently, a GITRL-GITR signaling loop in developing sympathetic neurons has been shown to be crucial for NGFpromoted axon growth in vitro and the establishment of sympathetic innervation in vivo (O'Keeffe et al., 2008). Our current study provides the first evidence for a role for LIGHT-HVEM signaling in the nervous system and supports the growing realization that TNFSF is extensively involved in regulating the growth of neural processes during development.

\section{References}

Bossen C, Ingold K, Tardivel A, Bodmer JL, Gaide O, Hertig S, Ambrose C, Tschopp J, Schneider P (2006) Interactions of tumor necrosis factor (TNF) and TNF receptor family members in the mouse and human. J Biol Chem 281:13964-13971.

Chen MC, Hwang MJ, Chou YC, Chen WH, Cheng G, Nakano H, Luh TY, Mai SC, Hsieh SL (2003) The role of apoptosis signal-regulating kinase 1 in lymphotoxin-beta receptor-mediated cell death. J Biol Chem 278:16073-16081.

Davies AM (2003) Regulation of neuronal survival and death by extracellular signals during development. EMBO J 22:2537-2545.

Davies AM, Lee KF, Jaenisch R (1993) p75-deficient trigeminal sensory neurons have an altered response to NGF but not to other neurotrophins. Neuron 11:565-574.

Desbarats J, Birge RB, Mimouni-Rongy M, Weinstein DE, Palerme JS, Newell MK (2003) Fas engagement induces neurite growth through ERK activation and p35 upregulation [see comment]. Nat Cell Biol 5:118-125.

ElShamy WM, Ernfors P (1997) Brain-derived neurotrophic factor, neurotrophin-3, and neurotrophin-4 complement and cooperate with each other sequentially during visceral neuron development. J Neurosci 17:8667-8675.

Gallagher D, Gutierrez H, Gavalda N, O’Keeffe G, Hay R, Davies AM (2007) Nuclear factor $-\kappa \mathrm{B}$ activation via tyrosine phosphorylation of inhibitor $\kappa \mathrm{B}-\alpha$ is crucial for ciliary neurotrophic factor-promoted neurite growth from developing neurons. J Neurosci 27:9664-9669.

Golan H, Levav T, Mendelsohn A, Huleihel M (2004) Involvement of tumor necrosis factor alpha in hippocampal development and function. Cereb Cortex 14:97-105.

Gommerman JL, Browning JL (2003) Lymphotoxin/light, lymphoid microenvironments and autoimmune disease. Nat Rev Immunol 3:642-655.

Grivennikov SI, Kuprash DV, Liu ZG, Nedospasov SA (2006) Intracellular signals and events activated by cytokines of the tumor necrosis factor superfamily: from simple paradigms to complex mechanisms. Int Rev Cytol 252:129-161.

Gutierrez H, Davies AM (2007) A fast and accurate procedure for deriving the Sholl profile in quantitative studies of neuronal morphology. J Neurosci Methods 163:24-30.

Gutierrez H, Hale VA, Dolcet X, Davies A (2005) NF-kB signalling regulates the growth of neural processes in the developing peripheral and central nervous systems. Development 132:1713-1726.

Gutierrez H, O'Keeffe GW, Gavaldà N, Gallagher D, Davies AM (2008) Nuclear factor $\kappa \mathrm{B}$ signaling either stimulates or inhibits neurite growth depending on the phosphorylation status of p65/RelA. J Neurosci 28:8246-8256.

Hehlgans T, Pfeffer K (2005) The intriguing biology of the tumour necrosis factor/tumour necrosis factor receptor superfamily: players, rules and the games. Immunology 115:1-20.

Hikichi Y, Matsui H, Tsuji I, Nishi K, Yamada T, Shintani Y, Onda H (2001) LIGHT, a member of the TNF superfamily, induces morphological changes and delays proliferation in the human rhabdomyosarcoma cell line RD. Biochem Biophys Res Commun 289:670-677.

Marsters SA, Ayres TM, Skubatch M, Gray CL, Rothe M, Ashkenazi A (1997) Herpesvirus entry mediator, a member of the tumor necrosis factor receptor (TNFR) family, interacts with members of the TNFR-associated factor family and activates the transcription factors NF-kappaB and AP-1. J Biol Chem 272:14029-14032.

Matsui H, Hikichi Y, Tsuji I, Yamada T, Shintani Y (2002) LIGHT, a member of the tumor necrosis factor ligand superfamily, prevents tumor necrosis factor-alpha-mediated human primary hepatocyte apoptosis, but not Fas-mediated apoptosis. J Biol Chem 277:50054-50061.

Morishita R, Sugimoto T, Aoki M, Kida I, Tomita N, Moriguchi A, Maeda K, Sawa Y, Kaneda Y, Higaki J, Ogihara T (1997) In vivo transfection of cis element "decoy" against nuclear factor-kappaB binding site prevents myocardial infarction. Nat Med 3:894-899.

Murphy KM, Nelson CA, Sedý JR (2006) Balancing costimulation and inhibition with BTLA and HVEM. Nat Rev Immunol 6:671-681.

Neumann H, Schweigreiter R, Yamashita T, Rosenkranz K, Wekerle H, Barde YA (2002) Tumor necrosis factor inhibits neurite outgrowth and branching of hippocampal neurons by a rho-dependent mechanism. J Neurosci 22:854-862.

O'Keeffe GW, Gutierrez H, Pandolfi PP, Riccardi C, Davies AM (2008) NGF-promoted axon growth and target innervation requires GITRLGITR signaling. Nat Neurosci 11:135-142.

Pierer M, Brentano F, Rethage J, Wagner U, Hantzschel H, Gay RE, Gay S, Kyburz D (2007) The TNF superfamily member LIGHT contributes to survival and activation of synovial fibroblasts in rheumatoid arthritis. Rheumatology 46:1063-1070.

Rooney IA, Butrovich KD, Glass AA, Borboroglu S, Benedict CA, Whitbeck JC, Cohen GH, Eisenberg RJ, Ware CF (2000) The lymphotoxin-beta receptor is necessary and sufficient for LIGHT-mediated apoptosis of tumor cells. J Biol Chem 275:14307-14315.

Shao Z, Browning JL, Lee X, Scott ML, Shulga-Morskaya S, Allaire N, Thill G, Levesque M, Sah D, McCoy JM, Murray B, Jung V, Pepinsky RB, Mi S (2005) TAJ/TROY, an orphan TNF receptor family member, binds Nogo-66 receptor 1 and regulates axonal regeneration. Neuron 45:353-359.

Tanabe K, Bonilla I, Winkles JA, Strittmatter SM (2003) Fibroblast growth factor-inducible-14 is induced in axotomized neurons and promotes neurite outgrowth. J Neurosci 23:9675-9686.

Ware CF (2005) Network communications: lymphotoxins, LIGHT, and TNF. Annu Rev Immunol 23:787-819.

Wei CY, Chou YH, Ho FM, Hsieh SL, Lin WW (2006) Signaling pathways of LIGHT induced macrophage migration and vascular smooth muscle cell proliferation. J Cell Physiol 209:735-743.

Zou GM, Hu WY (2005) LIGHT regulates CD86 expression on dendritic cells through NF-kappaB, but not JNK/AP-1 signal transduction pathway. J Cell Physiol 205:437-443.

Zuliani C, Kleber S, Klussmann S, Wenger T, Kenzelmann M, Schreglmann N, Martinez A, del Rio JA, Soriano E, Vodrazka P, Kuner R, Groene HJ, Herr I, Krammer PH, Martin-Villalba A (2006) Control of neuronal branching by the death receptor CD95 (Fas/Apo-1). Cell Death Differ 13:31-40. 